\title{
MABEL photon-counting laser altimetry data in Alaska for ICESat-2 simulations and development
}

\author{
Kelly M. Brunt ${ }^{1,2}$, Thomas A. Neumann ${ }^{2}$, Jason M. Amundson ${ }^{3}$, Jeffrey L. Kavanaugh ${ }^{4}$, Mahsa S. Moussavi ${ }^{5,6}$, \\ Kaitlin M. Walsh ${ }^{2,7}$, William B. Cook ${ }^{2}$, and Thorsten Markus ${ }^{2}$ \\ ${ }^{1}$ Earth System Science Interdisciplinary Center (ESSIC), University of Maryland, College Park, MD, USA \\ ${ }^{2}$ NASA Goddard Space Flight Center, Greenbelt, MD, USA \\ ${ }^{3}$ Department of Natural Sciences, University of Alaska Southeast, Juneau, AK, USA \\ ${ }^{4}$ Department of Earth and Atmospheric Sciences, University of Alberta, Edmonton, AB, Canada \\ ${ }^{5}$ Cooperative Institute for Research in Environmental Sciences (CIRES), University of Colorado, Boulder, CO, USA \\ ${ }^{6}$ National Snow and Ice Data Center (NSIDC), CIRES, University of Colorado, Boulder, CO, USA \\ ${ }^{7}$ Stinger Ghaffarian Technologies, Inc., Greenbelt, MD, USA
}

Correspondence to: Kelly M. Brunt (kelly.m.brunt@nasa.gov)

Received: 10 December 2015 - Published in The Cryosphere Discuss.: 19 January 2016

Revised: 1 July 2016 - Accepted: 11 July 2016 - Published: 10 August 2016

\begin{abstract}
Ice, Cloud, and land Elevation Satellite-2 (ICESat2) is scheduled to launch in late 2017 and will carry the Advanced Topographic Laser Altimeter System (ATLAS), which is a photon-counting laser altimeter and represents a new approach to satellite determination of surface elevation. Given the new technology of ATLAS, an airborne instrument, the Multiple Altimeter Beam Experimental Lidar (MABEL), was developed to provide data needed for satellite-algorithm development and ICESat-2 error analysis. MABEL was deployed out of Fairbanks, Alaska, in July 2014 to provide a test dataset for algorithm development in summer conditions with water-saturated snow and ice surfaces. Here we compare MABEL lidar data to in situ observations in Southeast Alaska to assess instrument performance in summer conditions and in the presence of glacier surface melt ponds and a wet snowpack. Results indicate the following: (1) based on MABEL and in situ data comparisons, the ATLAS $90 \mathrm{~m}$ beam-spacing strategy will provide a valid assessment of across-track slope that is consistent with shallow slopes $\left(<1^{\circ}\right)$ of an ice-sheet interior over 50 to $150 \mathrm{~m}$ length scales; (2) the dense along-track sampling strategy of photon counting systems can provide crevasse detail; and (3) MABEL $532 \mathrm{~nm}$ wavelength light may sample both the surface and subsurface of shallow (approximately $2 \mathrm{~m}$ deep) supraglacial melt ponds. The data associated with crevasses
\end{abstract}

and melt ponds indicate the potential ICESat-2 will have for the study of mountain and other small glaciers.

\section{Introduction}

Ice, Cloud, and land Elevation Satellite-2 (ICESat-2) is a NASA mission scheduled to launch in 2017. ICESat-2 is a follow-on mission to ICESat (2003-2009) and will extend the time series of elevation-change measurements aimed at estimating the contribution of polar ice sheets to eustatic sea level rise. ICESat-2 will carry the Advanced Topographic Laser Altimeter System (ATLAS), which uses a different surface detection strategy than the instrument onboard ICESat. Abdalati et al. (2010) provide an early overview of the ATLAS concept and overall design. While the measurement goals of ATLAS remain as described in Abdalati et al. (2010), some of the details have evolved (Markus et al., 2016). ATLAS is a six-beam, photon-counting laser altimeter (Fig. 1). In a photon-counting system, singlephoton sensitive detectors are used to record arrival time of any detected photon. ATLAS will use short ( $<2 \mathrm{~ns}) 532 \mathrm{~nm}$ (green) wavelength laser pulses, with a $10 \mathrm{kHz}$ repetition rate, which yields a $\sim 0.70 \mathrm{~m}$ along-track sampling interval, and $\mathrm{a} \sim 17 \mathrm{~m}$ diameter footprint. An accurate assessment of ice-sheet surface-elevation change based on altimetry is de- 


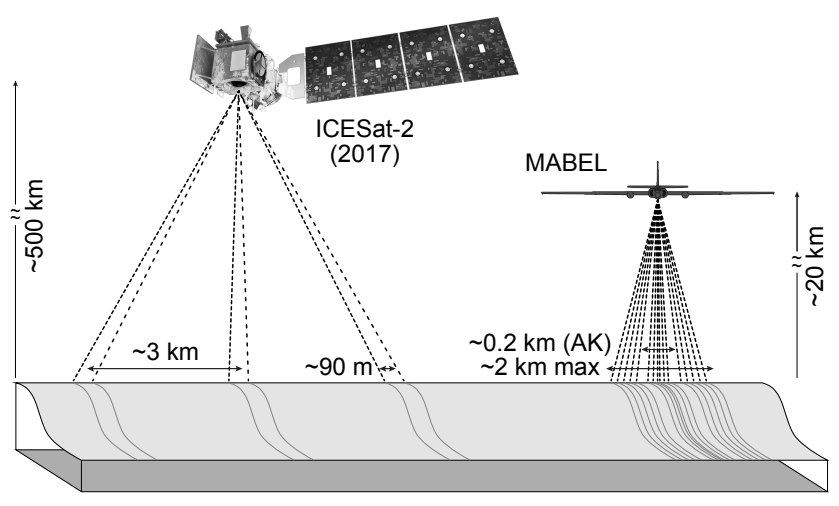

Figure 1. Schematic ICESat-2 and MABEL beam geometry (dashed lines) and reference ground tracks (grey lines along icesheet surface). ICESat-2 beam pairs (separated by $\sim 90 \mathrm{~m}$ ) do not have the same energy in order to keep the required laser energy low; therefore, each beam pair consists of a strong and a weak beam (as indicated by the dash difference). MABEL allows for beamgeometry changes with a maximum ground spacing of $\sim 2 \mathrm{~km}$ at $20 \mathrm{~km}$. However, for the 2014 AK deployment, the maximum ground spacing was $0.2 \mathrm{~km}$ (after Brunt et al., 2014).

pendent upon knowledge of local slope (Zwally et al., 2011). Therefore, the six ATLAS beams are arranged into three sets of pairs. Spacing between the three pair sets is $\sim 3 \mathrm{~km}$ to increase sampling density, while spacing between each beam within a given pair will be $\sim 90 \mathrm{~m}$ to make the critical determination of local slope on each pass. Therefore, elevation change can be determined from only two passes of a given area (Brunt et al., 2014).

Given this new approach to satellite surface elevation measurement, an airborne instrument, the Multiple Altimeter Beam Experimental Lidar (MABEL), was developed to (1) enable the development of ICESat-2 geophysical algorithms prior to launch and (2) enable ICESat-2 error analysis. MABEL (discussed in detail in McGill et al., 2013) is a multibeam, photon-counting lidar, sampling at both 532 (green) and $1064 \mathrm{~nm}$ (near infrared) wavelengths using short $(\sim 1.5 \mathrm{~ns})$ laser pulses. The dual wavelength instrument design was intended to assess green-wavelength light penetration in water or snow (McGill et al., 2013). Deems et al. (2013) provide a review of lidar use for snow studies and describe how light at 532 and $1064 \mathrm{~nm}$ wavelengths interacts with snow surfaces. Light penetration into a snow surface is a function of both grain size (with larger snow-grain size resulting in increased volumetric scattering, and therefore increased light penetration) and wavelength (with $532 \mathrm{~nm}$ light having lower absorption than $1064 \mathrm{~nm}$ light, which ultimately produces increased light penetration at the shorter wavelength). Deems et al. (2013) also note that light penetration into snow surfaces is extremely difficult to accurately measure.

Following engineering test flights in 2010 and 2011, MABEL was deployed to Greenland (April 2012) and Alaska
(July 2014) to collect data, including from glacier targets, and to assess elements of the resulting data that may vary seasonally. The Greenland 2012 campaign sampled winterlike conditions, while the Alaska 2014 campaign was timed to collect data during the summer melt season, which is characterized by open crevasses and surface melt ponds. In winter, increased albedo, reduced ice-sheet surface roughness, and reduced solar background and backscatter in the atmosphere all lead to an increased signal-to-noise ratio and an increase in photon-retrieval density (i.e., the number of, and temporal distribution of photons transmitted and recorded by the lidar). In general, with increased photon-retrieval density, we expect better surface measurement precision. In the extreme case, the photon-retrieval density may be sufficiently high that the instrument receiver does not have the time required to process the incoming photon information before receiving more. This effect is referred to as "instrument dead time" and can produce a positive surface elevation bias. In summer, reduced albedo, increased ice-sheet surface roughness, and increased solar background leads to a decrease in photon-retrieval density and signal-to-noise ratios, compromising measurement precision. The Alaska 2014 campaign also aimed to investigate how light at 532 and $1064 \mathrm{~nm}$ wavelengths interacts with the surface in melting conditions, and how this may affect the statistics of the $532 \mathrm{~nm}$ signal photons and overall elevation accuracy.

Here, we compare in situ measurements with MABEL airborne lidar data on the Bagley (16 July $2014 ; 60.5^{\circ} \mathrm{N}$, $141.7^{\circ} \mathrm{W}$ ) and Juneau (31 July $2014 ; 58.6^{\circ} \mathrm{N}, 134.2^{\circ} \mathrm{W}$ ) icefields in Southeast Alaska (Fig. 2). These comparisons are made with consideration for the planned ATLAS beam geometry in order to investigate instrument performance in summer conditions and in the presence of surface crevasses and melt ponds.

\section{Data and methods}

\subsection{MABEL data}

MABEL data (Level 2A, release 9) for the Alaska 2014 campaign (Fig. 2) are available from the NASA ICESat-2 website (http://icesat.gsfc.nasa.gov/icesat2/data/ mabel/mabel_docs). Each data file contains $1 \mathrm{~min}$ of data for every available beam (approximately two beams per deployment were compromised due to instrumentation issues). The data files contain photon arrival times resulting from reflected laser light (i.e., signal photons), solar background and backscatter in the atmosphere (i.e., background photons), and to a lesser degree detector noise (i.e., noise photons). A histogram-based surface-finding algorithm developed at NASA Goddard Space Flight Center (GSFC) was used to discriminate signal photons from background and noise photons. The algorithm is based on histograms of photon arrival times in $25 \mathrm{~m}$ along-track segments and $10 \mathrm{~m}$ vertical bins 


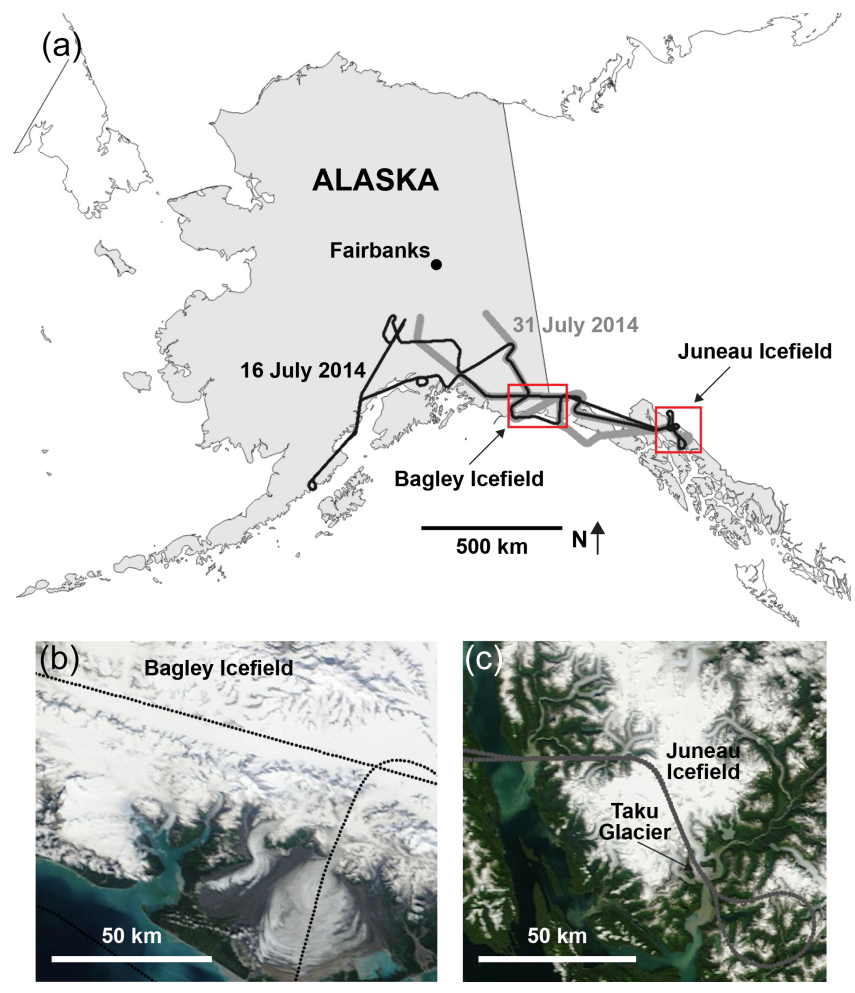

Figure 2. Map of the Multiple Altimeter Beam Experimental Lidar (MABEL) flights used in this analysis from the July 2014 field campaign, which was based out of Fort Wainwright, Fairbanks, Alaska. (a) Overview map, indicating the 16 and 31 July 2014 flight paths. (b) Inset of the Bagley Icefield, showing the 16 July 2014 flight path. (c) Inset of the Juneau Icefield, showing the 31 July 2014 flight path and the Taku Glacier. Both insets are shown with 31 July 2104 MODIS imagery.

and assumes a random distribution of background photons and a symmetric return pulse. Further details of this surfacefinding algorithm are described in Brunt et al. (2014). The GSFC algorithm is applicable to a wide range of surface types, while most ICESat- 2 standard data product algorithms are surface-type specific (e.g., glacier, sea ice, ocean, vegetation) and more rigorous with respect to returns identified as surface signal. The derived surface elevations are reported relative to the WGS84 ellipsoid.

The MABEL laser pulse repetition rate is variable ( 5 to $25 \mathrm{kHz})$ and was $5 \mathrm{kHz}$ for the data presented here. At this nominal altitude and repetition rate, and at an aircraft speed of $\sim 200 \mathrm{~m} \mathrm{~s}^{-1}$, MABEL samples a $\sim 2 \mathrm{~m}$ footprint every $\sim 0.04$ m along-track.

MABEL beams are arranged approximately linearly, perpendicular to the direction of flight, with the $1064 \mathrm{~nm}$ beams leading the $523 \mathrm{~nm}$ beams by $\sim 60 \mathrm{~m}$. The system allows for beam-geometry changes between flights with a maximum beam spread of $\sim 2 \mathrm{~km}$ given the $20 \mathrm{~km}$ nominal altitude of the NASA ER-2 aircraft. The beam configuration for the Alaska 2014 campaign had total swath width of $200 \mathrm{~m}$
(Fig. 1). The spacing between the individual beams was configured to allow simulation of the planned beam geometry of ATLAS. Previous results from the MABEL 2012 Greenland campaign suggest that the ATLAS beam geometry is appropriate for the determination of slope on $\sim 90 \mathrm{~m}$ across-track length scales, a measurement that will be fundamental to accounting for the effects of local surface slope from the icesheet surface-elevation change derived from ATLAS (Brunt et al., 2014).

Relative to one another, the MABEL beams have nonuniform average transmit energy. While all beams originate from a single $1064 \mathrm{~nm}$ laser source, each beam follows a unique optical path through the instrument once split from the source beam. Several individual beams maintain the fundamental $1064 \mathrm{~nm}$ wavelength of the source, while others are split off of a beam that is frequency-doubled to $532 \mathrm{~nm}$ (McGill et al., 2013). Owing to the frequency-doubling process and the non-uniform optical paths (fiber lengths) through the instrument, the 1064 and $523 \mathrm{~nm}$ transmit-pulse energies are generally not equal. During the 2014 Alaska campaign, there were fifteen $532 \mathrm{~nm}$ beams and six $1064 \mathrm{~nm}$ beams.

Our analysis used relatively high-energy beams. For analyses intended to mimic the $90 \mathrm{~m}$ spacing of the ATLAS beam geometry, two $1064 \mathrm{~nm}$ beams were chosen based on their across-track ground separation and along-track signalphoton density: beams 43 (center of the array) and 48 ( $\sim 90 \mathrm{~m}$ to the left of the array center across-track). For analyses intended to assess issues that might be wavelengthdependent, beams $5(532 \mathrm{~nm})$ and $50(1064 \mathrm{~nm})$ were chosen because they were in line with one another in the along-track direction and approximately $35 \mathrm{~m}$ across-track to the left of the array center.

Because of the different optical paths each beam takes through the instrument, each MABEL beam has a unique range bias (McGill et al., 2013). Prior to Level 2A data processing, MABEL ranges are corrected for these channelspecific optical path lengths using a calibration derived from data recorded during aircraft pitch and roll maneuvers performed over stretches of open ocean. We assume that this calibration mitigates the larger channel biases, including those associated with errors in pointing. However, other smallerscale channel biases may still exist; these smaller-scale channel bias corrections were on the order of decimeters. Much of the analysis performed here, such as evaluation of local surface slope, did not require absolute range accuracy. Therefore, the individual beams were generally only calibrated with respect to one another based on data collected over the nearest flat surface (e.g., open water). These calibrations were made relative to the beam closest to the center of the array. 


\subsection{MABEL camera imagery}

For the 2014 Alaska campaign, a camera was integrated with MABEL and was successful for over $40 \%$ of the campaign's duration. The images were typically used to visually confirm the type of surface being overflown by MABEL (e.g., ice, open water, sea ice, or melt ponds) or to confirm the presence or absence of clouds. These images are also available on the ICESat-2 website. The MABEL camera (Sony Nex7, with a 55 to $220 \mathrm{~mm}, f / 4.5-6.6$ telephoto lens) was mounted on the same optical bench as the MABEL telescopes and shared the same portal in the aircraft. For the 2014 Alaska campaign, a focal length of $210 \mathrm{~mm}$ was used for the duration of the campaign. The camera produced 6000 by 4000 pixel color images. At a nominal aircraft altitude of $20 \mathrm{~km}$, each image covers an approximately 2.25 by $1.5 \mathrm{~km}$ area, or approximately $3 \mathrm{~m}$ per pixel at sea level. Images were taken every $3 \mathrm{~s}$, which provided approximately $30 \%$ overlap between images. The images collected were not systematically georeferenced; however, they were time-stamped based on MABEL instrument timing to provide a first-order assessment of the surface that the lidar had surveyed.

\subsection{Landsat 8 and WorldView-2 imagery}

Data from the Landsat 8 Operational Land Imager (OLI) of the Bagley Icefield (Fig. 2b) were used as an independent assessment of the depths of melt ponds surveyed by MABEL. We applied spectrally based depth retrieval models to Landsat 8 imagery (Moussavi et al., 2016; Moussavi, 2015; Pope et al., 2016), which were calibrated based on data from supraglacial lakes in Greenland. We assessed the performance of OLI's coastal blue, blue, green, red, and panchromatic channels in retrieving supraglacial lake depths. Ultimately, the models establish a relationship between Landsat 8 top-of-atmosphere (TOA) comparing pre-drainage spectral reflectance values over the lakes with a post-drainage digital elevation model (DEM), derived from WorldView-2 imagery acquired from the Polar Geospatial Center at the University of Minnesota, using image-processing software (ERDAS). Our analysis indicated that, for shallow lakes (depth $<5 \mathrm{~m}$ ), red and panchromatic band data are most suitable for supraglacial bathymetry. Because of the relatively small size of the lakes in our study area, we chose the panchromatic channel for the better spatial resolution.

A second WorldView-2-derived DEM was used near the terminus of the Lower Taku Glacier (Fig. 2c) to assess surface elevations derived from MABEL signal photons in steep and crevassed terrain. The DEM, created by the Polar Geospatial Center at the University of Minnesota, was extracted from high-resolution along-track stereo WorldView2 imagery processed with NASA's open-source Ames Stereo Pipeline software (Moratto et al., 2010). The WorldView2 images were collected on 6 June 2014, while the MABEL data were collected on 16 July 2014, and thus sepa- rated by 40 days. As part of an unrelated project, GPS data were continuously collected at six sites on the Lower Taku Glacier throughout the summer, using a Trimble NetR9 receiver; these data were used to tie the MABEL survey data to the WorldView-2 DEM. The data were processed kinematically using the Plate Boundary Observatory station AB50, located at the Mendenhall Glacier Visitor Center, approximately $20 \mathrm{~km}$ west of the survey area.

\subsection{Juneau Icefield GPS data}

Previous studies (Brunt et al., 2013, 2014) have demonstrated that MABEL precisely characterizes the ice-sheet surface when comparing MABEL-derived slope on $90 \mathrm{~m}$ acrosstrack length scales with those based on both Airborne Topographic Mapper (ATM; Krabill et al., 2002) and Laser Vegetation Imaging Sensor (LVIS, more recently referred to as Land Vegetation Ice Sensor; Blair et al., 1999).

We conducted a GPS survey on the Juneau Icefield (Fig. 2c) to determine the length scale at which a groundbased local slope assessment on a flat surface $\left(<1^{\circ}\right.$ slope $)$ begins to differ significantly from that of a $90 \mathrm{~m}$ across-track slope assessment. On 19 July 2014, we conducted differential GPS surveys of the nodes of a series of concentric equilateral triangles. WGS84 ellipsoidal heights, in a Universal Transverse Mercator map projection (UTM zone $8 \mathrm{~N}$ ), were determined for each node using Trimble 5700 base and rover receivers, operating in real-time differential mode. The basestation receiver was located at the Juneau Icefield Research Program (JIRP) Camp 10, approximately $1 \mathrm{~km}$ from where the rover receivers were operated. Eight triangles were surveyed with side lengths of $5,10,25,50,75,90,125$, and $150 \mathrm{~m}$ (Fig. 3, black points). We fit a surface to each of the eight triangles and then calculated the surface slope in both the UTM easting and northing directions (surface gradients $\delta z / \delta x$ and $\delta z / \delta y)$.

MABEL-based surface gradients $\delta z / \delta x$ and $\delta z / \delta y$ were generated from data from the 31 July 2014 flight and compared with the GPS-based surface gradients. We used beams 43 and $48(1064 \mathrm{~nm})$, which had relatively high along-track signal-photon density and approximately $90 \mathrm{~m}$ ground spacing, and intersected the GPS survey array (Fig. 3, red lines). The MABEL beams were cross-calibrated to remove the relative elevation bias resulting from their different optical paths through the instrument. To accomplish this calibration, we chose beam 43 as a reference beam, calculated the mean difference between the elevation of the signal photons of the reference beam and beam 48 over the nearest open ocean, and removed that offset $(0.2 \mathrm{~m})$ from beam 48 . We assumed that the calibration remained valid for the $75 \mathrm{~km}$ between the open ocean and the GPS survey area. We projected the geodetic MABEL data to the gridded map projection of the GPS data (UTM zone 8N) to facilitate direct comparisons and so that changes in elevation in both the easting and northing directions (surface gradients $\delta z / \delta x$ and $\delta z / \delta y$ ) could 


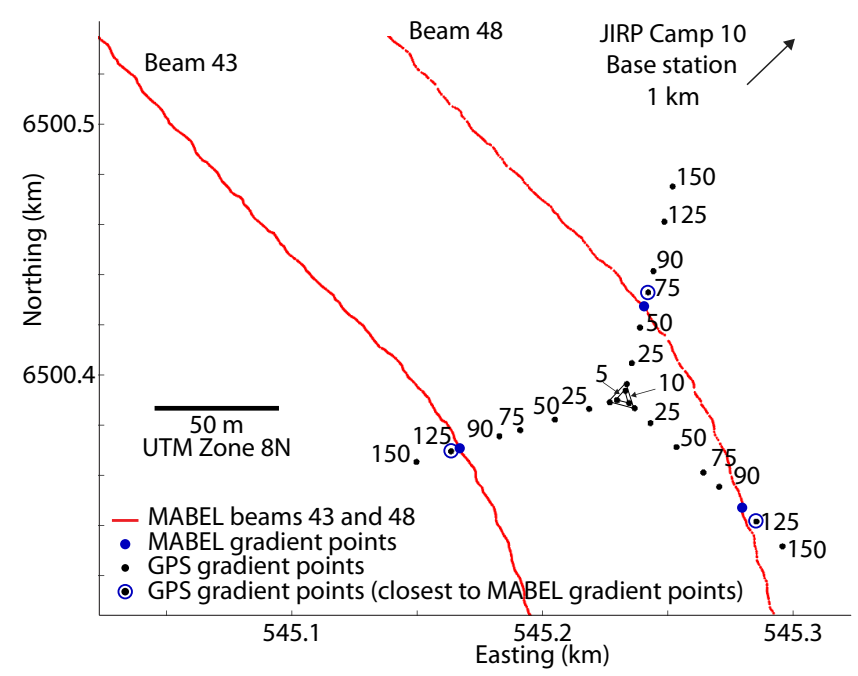

Figure 3. GPS survey on the Juneau Icefield. Ground tracks for MABEL beams 43 and 48, from the 31 July 2014 flight, are indicated (red lines). GPS survey points of the nodes of concentric, equilateral triangles, with side lengths of $5,10,25,50,75,90,125$, and $150 \mathrm{~m}$, are indicated (black points). Also indicated are the intersections of the MABEL flight lines with the GPS survey grid (blue solid points), which were used to calculate MABEL surface gradients $(\delta z / \delta x$ and $\delta z / \delta y)$. The GPS sites that are the closest to the MABEL gradient points are also indicated (blue open circles). The overall slope, based on the MABEL elevations at the points of intersections with the GPS survey grid (blue solid points), is approximately $0.5^{\circ}$.

be treated uniformly. We generated a MABEL triangle, with nodes based on the intersections of the GPS survey and the ground tracks of the MABEL beams (Fig. 3, blue solid points). Elevations at those nodes were determined by taking an average of the elevations of the signal photons within a $5 \mathrm{~m}$ radius of those points, to take into account MABEL horizontal geolocation uncertainty. We then fit a $1 \mathrm{~m}$ by $1 \mathrm{~m}$ gridded surface to those points and calculated the associated MABEL surface gradient in both the easting and northing directions $(\delta z / \delta x$ and $\delta z / \delta y)$. Based on this surface, the local slope for the survey area was determined to be $0.5^{\circ}$, or comparable to what we expect for an ice-sheet interior. Finally, we generated a surface based on the three GPS survey sites that were closest to the nodes that defined the MABEL surface (Fig. 3, blue open circles).

We compared the MABEL-derived slopes to the slopes from each of the concentric GPS triangles and the slope based on the GPS survey sites that were closest to the nodes that defined the MABEL surface. Specifically, we created a surface gradient comparison (SGC) parameter for each of the GPS-derived triangles $(i)$ by calculating the square root of the sum of the squares (RSS) of the differences between the MABEL-derived and GPS-derived slopes in both the easting and northing ( $x$ and $y)$ directions:

$\operatorname{SGC}_{(i)}=$

$\sqrt{\left[(\delta z / \delta x)_{\mathrm{MABEL}}-(\delta z / \delta x)_{\mathrm{GPS}_{(i)}}\right]^{2}+\left[(\delta z / \delta y)_{\mathrm{MABEL}}-(\delta z / \delta y)_{\mathrm{GPS}_{(i)}}\right]^{2}}$,

where $\delta z / \delta x$ and $\delta z / \delta y$ are the surface gradients associated with both MABEL and each of the GPS triangles $(i)$, in the easting and northing directions.

\section{Results}

\subsection{MABEL signal-photon density}

For illustrative purposes, we produced histograms of the MABEL surface return for the beams used in our analyses (Fig. 4; beams 5, 43, 48, and 50) from $3000 \mathrm{~m}$ of along-track data over a stretch of open ocean. We calibrated the beam elevations to one another to remove the unique beam elevation biases; relative bias corrections ranged from 0.03 to $0.73 \mathrm{~m}$. We then detrended the surface elevations based on a linear fit to the signal photons to remove any elevation differences associated with wind stress or the relatively small effects of ocean dynamic topography and geoid undulation. The detrending of each beam takes into account all of these effects; this correction ranged from 0.11 to $0.29 \mathrm{~m}$ over the $3000 \mathrm{~m}$ of along-track data used for this analysis. We then produced histograms using a $0.01 \mathrm{~m}$ vertical bin size. We determined the full width at half maximum (FWHM) for each of the beams, which ranged from $0.19 \mathrm{~m}$ in beam $5(532 \mathrm{~nm})$ to $0.31 \mathrm{~m}$ in beam $43(1064 \mathrm{~nm})$. From Fig. 4 , the relative differences in the signal strengths of the individual beams are evident from the non-uniform amplitudes of the photoncount distribution.

The MABEL signal often has a primary surface return and a second, weaker return approximately 0.5 to $1.5 \mathrm{~m}$ below the surface. This is due to unintended secondary pulses from the MABEL laser that occur under some operational conditions. The exact conditions for after-pulsing are not completely understood, but are most likely the result of temperature drifts in the fundamental laser system. These occur due to changing environmental conditions within the instrument pod in the aircraft, and/or changes in efficiency of the coolant system. The cooling system relies upon passive external fins exposed to ambient cold conditions at altitude, and these conditions (temperature, airflow) change during flight. The secondary laser pulses are primarily seen in the $1064 \mathrm{~nm}$ returns and are minimized when the $1064 \mathrm{~nm}$ source is frequency-doubled to generate $532 \mathrm{~nm}$ beams. This second pulse can affect statistics associated with MABEL results and was therefore manually removed. This secondary pulse is evident in the openocean data example at approximately $0.75 \mathrm{~m}$ below the main surface return (Fig. 4).

Given nearly uniform surface conditions, along-track signal-photon density for each beam varied within and be- 


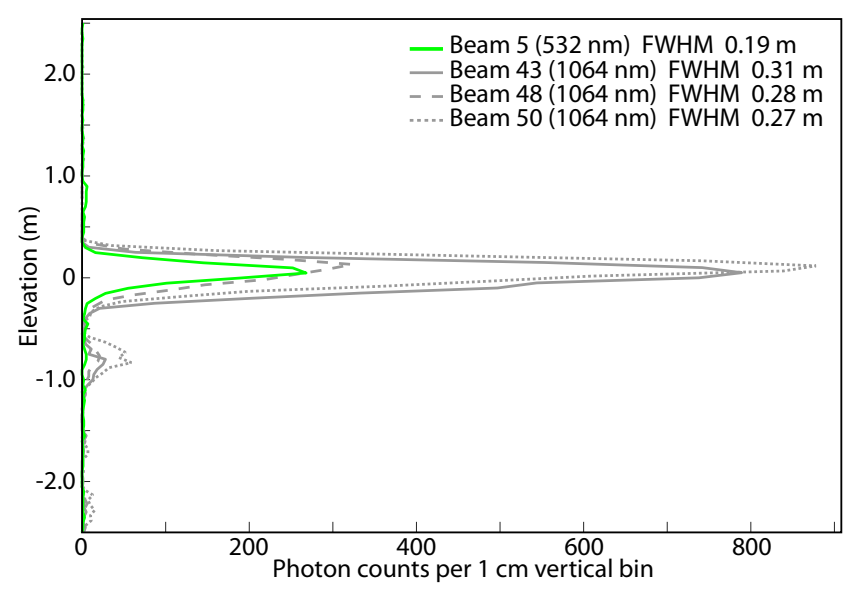

Figure 4. Histograms of the signal return for the MABEL beams used in this analysis $(5,43,48$, and 50). Plotted are ocean surfacereturn photon counts (per $0.01 \mathrm{~m}$ vertical bins) over a $3 \mathrm{~km}$ alongtrack distance against elevation $(\mathrm{m})$. The elevations are calibrated to one another and detrended. The full width at half maximum (FWHM) for each histogram is indicated in the legend. The secondary return $0.75 \mathrm{~m}$ below the main signal return, which is more evident in the $1064 \mathrm{~nm}$ beams, is due to unintended secondary pulses from the MABEL laser that occur under some operational conditions; this was removed for FWHM analysis.

tween flights based on parameters such as weather conditions, time of day, and sun-incidence angle. The signalphoton densities on the Juneau and Bagley icefields, for each beam considered here, are given in Table 1 . These densities are reported based on $0.70 \mathrm{~m}$ along-track length scales for direct comparison with previous results (Brunt et al., 2014), to mimic the ATLAS sampling interval (one laser shot every $0.70 \mathrm{~m}$ ). MABEL along-track signal-photon densities for the July 2014 Alaska campaign were lower than those reported during the April 2012 Greenland campaign by Brunt et al. (2014). They reported 3.4 and 3.9 signal photons per $0.70 \mathrm{~m}$ for beams 5 and $6(532 \mathrm{~nm})$, respectively, over the Greenland Ice Sheet; the highest counts of signal photons per $0.70 \mathrm{~m}$ were 1.8 and 3.7 for 532 and $1064 \mathrm{~nm}$ channels, respectively (Table 1). Some of this variation may have been related to seasonal differences in surface reflectivity between the two campaigns, which include parameters such as the freshness of the most recent snowfall, the dust content of the surface, the presence (or absence) of surface melt and ponds, and the presence (or absence) of snow bridges that cover crevasses. Some variation may also have been related to instrumentation issues, such as cleanliness of the elements in the optics.

The MABEL signal-photon densities (Table 1) are generally lower than those expected for ATLAS. Under similar conditions as the 2014 MABEL summer campaign and based on performance models, we expect the strong beams of ATLAS to record 7.6 signal photons every shot (or $0.70 \mathrm{~m}$ along track) over ice sheets and 0.5 to 1.8 signal photons ev-
Table 1. MABEL along-track signal photon densities over the open ocean and the Juneau and Bagley icefields.

\begin{tabular}{lccc}
\hline & \multicolumn{3}{c}{ MABEL surface-signal photons per $0.70 \mathrm{~m}$} \\
\hline Beam & $\begin{array}{l}\text { Open } \\
\text { ocean }\end{array}$ & $\begin{array}{c}\text { Juneau } \\
\text { Icefield }\end{array}$ & $\begin{array}{l}\text { Bagley } \\
\text { Icefield }\end{array}$ \\
\hline $5(532 \mathrm{~nm})$ & 0.3 & 1.8 & 1.7 \\
$43(1064 \mathrm{~nm})$ & 1.2 & 3.5 & 2.8 \\
$48(1064 \mathrm{~nm})$ & 0.5 & 1.5 & 1.0 \\
$50(1064 \mathrm{~nm})$ & 1.3 & 3.7 & 3.0 \\
ATLAS $^{1}$ & $0.5-1.8^{2}$ & $7.6^{3}$ & $7.6^{3}$ \\
\hline
\end{tabular}

${ }^{1}$ ATLAS instrument allocated performance. ${ }^{2}$ Dependent upon the wind state: 0.5 for high winds and 1.8 for low winds. ${ }^{3}$ This value is for summer conditions on an ice sheet; we note that, for summer ice sheets, the ATLAS performance model uses an albedo of 0.9 , which is more appropriate for ice with fresh snow or the interior of Antarctica.

ery shot over the open ocean, dependent upon the state of the wind (A. Martino, personal communication, 2016). We note that, for the Alaskan icefields, the expected number of signal photons based on the performance model is probably too high, as the model uses an albedo of 0.9 , which is more appropriate for ice with fresh snow or the interior of Antarctica than for icefields in Alaska in summer. Relative to the performance model, at best (i.e., using data from beam 50) the MABEL data used in this analysis suggest that the signal-photon densities were $\sim 72 \%$ of the expected ATLAS signal-photon densities over open ocean (with calm winds) and $\sim 49 \%$ of the expected ATLAS signal-photon densities over summer ice sheets.

\subsection{Elevation bias and uncertainty}

We compared MABEL elevations to those based on the Juneau Icefield GPS array, interpolated to the MABEL/GPS points of intersection (Fig. 3, blue solid points). The mean offset, or bias, for the three points of intersection was $3.2 \pm 0.1 \mathrm{~m}$. While this $\sim 3 \mathrm{~m}$ instrument bias is larger than that of other airborne lidars, it is within the MABEL design goals (algorithm development and error analysis), where instrument precision is more critical to satellite algorithm development than absolute accuracy. Thus, while other photoncounting systems are being used for change detection (e.g., Young et al., 2015), in its current configuration, MABEL is not suitable for time-series analysis of elevation change, either independently or when integrated with other datasets.

We assessed the surface precision of MABEL data (i.e., the spread of the MABEL data point cloud about a known surface, or the standard deviation of the mean difference between MABEL and a known surface elevation; Hodgson and Bresnahan, 2004) over the flat stretch of open ocean used in the analysis of Fig. 4. For approximately $3000 \mathrm{~m}$ of alongtrack open water, the surface-precision estimates for the strong 532 and $1064 \mathrm{~nm}$ beams, based on standard deviations of the mean differences from the detrended surface, were 
\pm 0.11 and $\pm 0.12 \mathrm{~m}$, respectively. Brunt et al. (2014) reported similar surface-precision values $( \pm 0.14 \mathrm{~m})$ based on direct comparison of MABEL elevation data with high-resolution ground-based GPS data (differentially post-processed with an $\mathrm{rms}<0.05 \mathrm{~m}$ ) over an airport departure apron. Further, Brunt et al. (2013) reported that, for all MABEL campaigns between 2010 and 2014 for which similar ground-based GPS data were available, MABEL surface precision ranged between \pm 0.11 and $\pm 0.24 \mathrm{~m}$. During that time period, MABEL had been deployed on two different types of aircraft and in a number of different optical configurations (McGill et al., 2013). These return pulse widths are dominated by the width of the MABEL transmit pulse $(\sim 1.5 \mathrm{~ns})$ and show relatively little pulse broadening due to surface slope or roughness.

\subsection{Surface characterization}

We examined MABEL data from the Bagley and Juneau icefields and from the Lower Taku Glacier to determine how well photon-counting laser altimeters would capture surface detail on relatively short length scales (less than $1 \mathrm{~km}$ ), such as crevasses and melt ponds.

Analysis of data from individual beams over the Bagley Icefield indicates that MABEL can capture surface detail of crevasse fields. Figure 5a shows stitched MABEL images of one set of crevasses on the Bagley Icefield; Fig. 5b shows MABEL signal and background photons for a $1200 \mathrm{~m}$ range that includes the glacier surface; and Fig. 5c shows MABEL signal photons, indicating returns from both the glacier surface and the bottoms of a series of crevasses. The along-track slope of this crevasse field, between 140.60 and $140.58^{\circ} \mathrm{W}$ longitude in Fig. 5c, is $1^{\circ}$.

Similarly, analysis of the individual beams in a different area of the Bagley Icefield indicated that MABEL can determine the location of melt ponds. Figure 6a shows stitched MABEL images from crevasse and melt-pond fields on the Bagley Icefield; Fig. 6b shows MABEL signal and background photons for a $1200 \mathrm{~m}$ range window that includes the glacier surface; Fig. 6c shows both signal and background photon-count densities (per 125 shots, or $\sim 2.5 \mathrm{~m}$ of alongtrack distance); and Fig. 6d shows MABEL signal photons, indicating the location of two melt ponds, which are approximately 50 and $70 \mathrm{~m}$ in along-track length. The along-track slope of this crevasse and melt pond field, between 141.91 and $141.93^{\circ} \mathrm{W}$ longitude in Fig. $6 \mathrm{~d}$, is $0.5^{\circ}$. A histogram of the signal photons associated with the larger melt pond in Fig. 6d is provided in Fig. 7. This figure depicts how light at 532 and $1064 \mathrm{~nm}$ wavelengths interacts with the surface of the melt pond, and how the melt pond affects the statistics of the $532 \mathrm{~nm}$ return signal. The FWHMs for the 532 and $1064 \mathrm{~nm}$ return signal were 0.26 and $0.34 \mathrm{~m}$, respectively. From Figs. 6 and 7 we observe that while no distinct features corresponding to the bottoms of the melt ponds are visible, an increased spread is apparent in the $532 \mathrm{~nm}$ histogram, likely associated with volumetric scattering throughout the ponds.

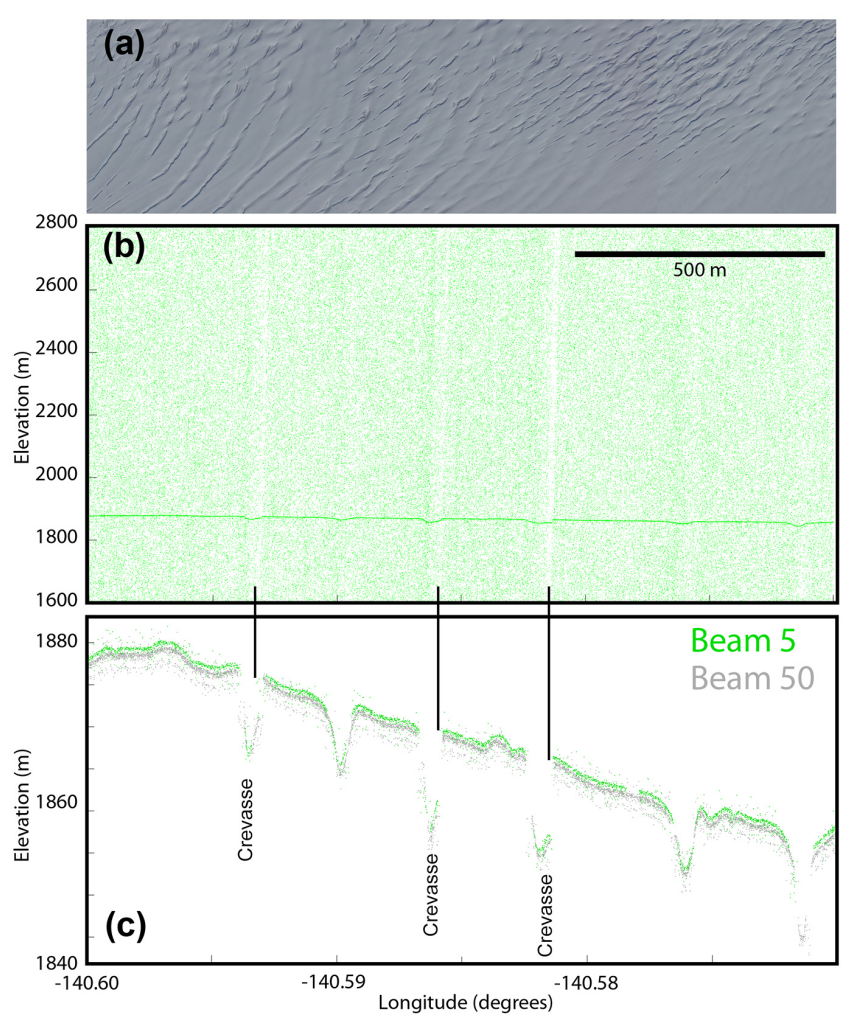

Figure 5. MABEL camera and photon data over a heavily crevassed section of the Bagley Icefield, from the 16 July 2014 flight. (a) Stitched MABEL camera images. (b) MABEL signal and background photons for a $1200 \mathrm{~m}$ range that includes the glacier surface. (c) MABEL signal photons, indicating both the surface and the bottoms of crevasses. The along-track slope of this field, between 140.60 and $140.58^{\circ} \mathrm{W}$ longitude, is $1^{\circ}$.

We applied spectrally based depth-retrieval models to Landsat 8 imagery (Moussavi et al., 2016; Moussavi, 2015; Pope et al., 2016) for an independent assessment of the depth of the melt-pond on the Bagley Icefield in Fig. 6d. This analysis indicated that melt ponds in this region were approximately $2 \mathrm{~m}$ deep.

Analysis of data from individual beams near the terminus of the Lower Taku Glacier (Fig. 8) demonstrates MABEL performance in regions with steeper slopes. The slope in this region is $4^{\circ}$ and is similar to slopes near ice-sheet margins; this slope also corresponds to the maximum slope angle used for ATLAS performance modeling over ice-sheet margins (A. Martino, personal communication, 2014). Figure 8a shows stitched MABEL camera images, which suggest a much rougher surface than that of the low-slope areas of interest on the Bagley Icefield examined in Fig. 6. Additionally, the MABEL ice-surface signal near the terminus was slightly compromised due to intermittent cloud cover, which attenuated the MABEL transmitted and/or received laser pulses. Further, when cloud cover allows for only intermittent surface determination, the surface-finding algorithm 

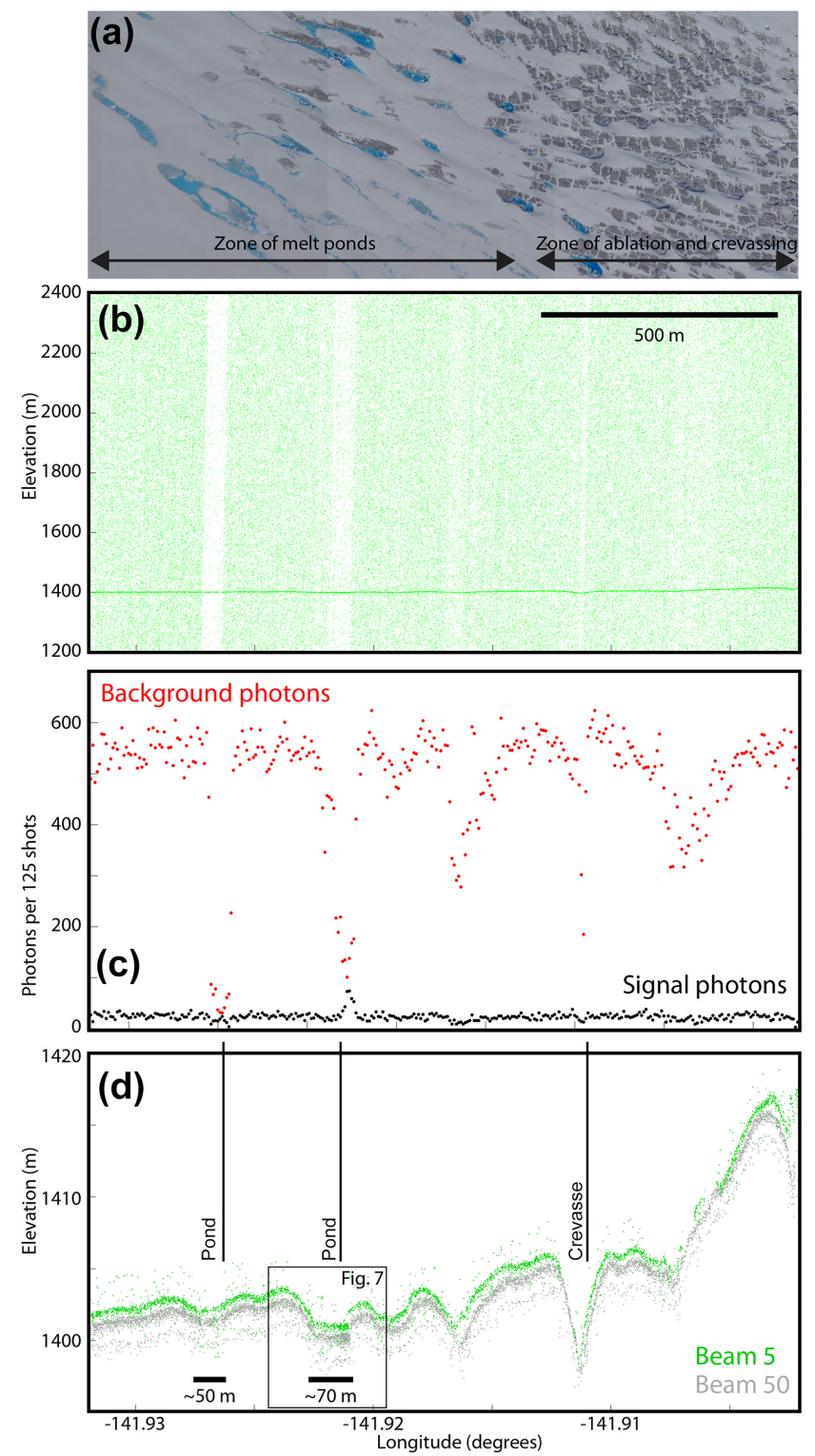

Figure 6. MABEL camera and photon data over crevasse and meltpond fields on the Bagley Icefield, from the 16 July 2014 flight. (a) Stitched MABEL camera images. (b) MABEL signal and background photons for a $1200 \mathrm{~m}$ range that includes the glacier surface. (c) Signal (black) and background (red) photon counts per 125 shots (approximately $2.5 \mathrm{~m}$ of along-track distance). (d) MABEL signal photons, indicating the location of melt ponds; the ponds indicated are approximately 50 and $70 \mathrm{~m}$ in along-track length. Figure 7 is a histogram of the $\sim 70 \mathrm{~m}$ pond. The $1064 \mathrm{~nm}$ beam shows evidence of a secondary return $1.5 \mathrm{~m}$ below the main signal return, due to unintended secondary pulses from the MABEL laser that occur under some operational conditions. The along-track slope of the crevasse field, between 141.93 and $141.91^{\circ} \mathrm{W}$ longitude, is approximately $0.5^{\circ}$.
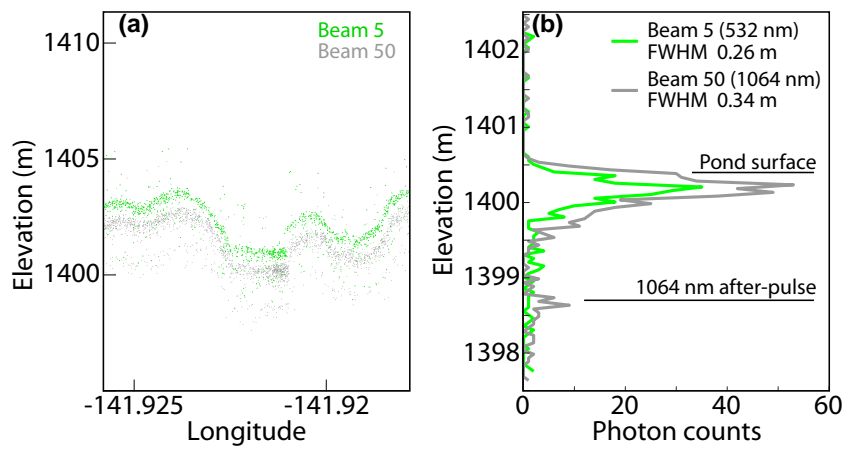

Figure 7. Surface return and histogram of the signal return for MABEL beams $5(532 \mathrm{~nm})$ and $50(1064 \mathrm{~nm})$ over the $\sim 70 \mathrm{~m}$ melt pond in Fig. 6. (a) MABEL signal photons over for beams 5 and 50 for the $70 \mathrm{~m}$ melt pond in Fig. 6. The $1064 \mathrm{~nm}$ beam shows evidence of a secondary return $1.5 \mathrm{~m}$ below the main signal return, due to unintended secondary pulses from the MABEL laser that occur under some operational conditions. (b) Plotted for each beam are surfacereturn photon counts per $0.01 \mathrm{~m}$ vertical bins against elevation $(\mathrm{m})$. The elevations of beams 5 and 50 are calibrated to one another. The full width at half maximum (FWHM) for each histogram is indicated in the legend. The secondary return $<1 \mathrm{~m}$ below the main signal return, which is more evident in the $1064 \mathrm{~nm}$ beam, is due to unintended secondary pulses from the MABEL laser that occur under some operational conditions; this was removed for FWHM analysis.

used to discriminate signal photons from background and noise photons is compromised.

MABEL-derived surface elevations over the Lower Taku Glacier were compared to elevations from the WorldView2-derived DEM (Fig. 8b), which had $2 \mathrm{~m}$ horizontal resolution. Figure $8 \mathrm{c}$ is one of the images used to create the DEM shown in Fig. 8d. The MABEL data were collected 40 days after the WorldView-2 images were acquired. GPS data from the Lower Taku Glacier were used to determine mean iceflow velocities to tie the two datasets together. Specifically, the MABEL ground tracks were migrated up ice flow, using the northing and easting components of the mean velocities derived from the GPS data, to more accurately compare MABEL surface elevations to those derived from the earlier WorldView-2 imagery. An elevation was then extracted from the WorldView-2 DEM for each migrated MABEL data point.

Mean ice-flow velocities varied substantially for the sites on the Lower Taku Glacier (Fig. 8c). A mean ice-flow velocity of $0.2 \mathrm{~m} \mathrm{day}^{-1}$ was recorded at the southern GPS site (SDWN, $800 \mathrm{~m}$ from the center of the MABEL ground track), while mean velocities for the two central GPS sites (C1 and SLFT, $1500 \mathrm{~m}$ from the center of the MABEL data ground track) were $0.7 \mathrm{~m} \mathrm{day}^{-1}$ and mean velocities for the three northern GPS sites (C2, SRIT, and SUP, $3000 \mathrm{~m}$ from the center of the MABEL data line) were $1.0 \mathrm{~m} \mathrm{day}^{-1}$. While the flow velocity at SDWN does not necessarily represent 

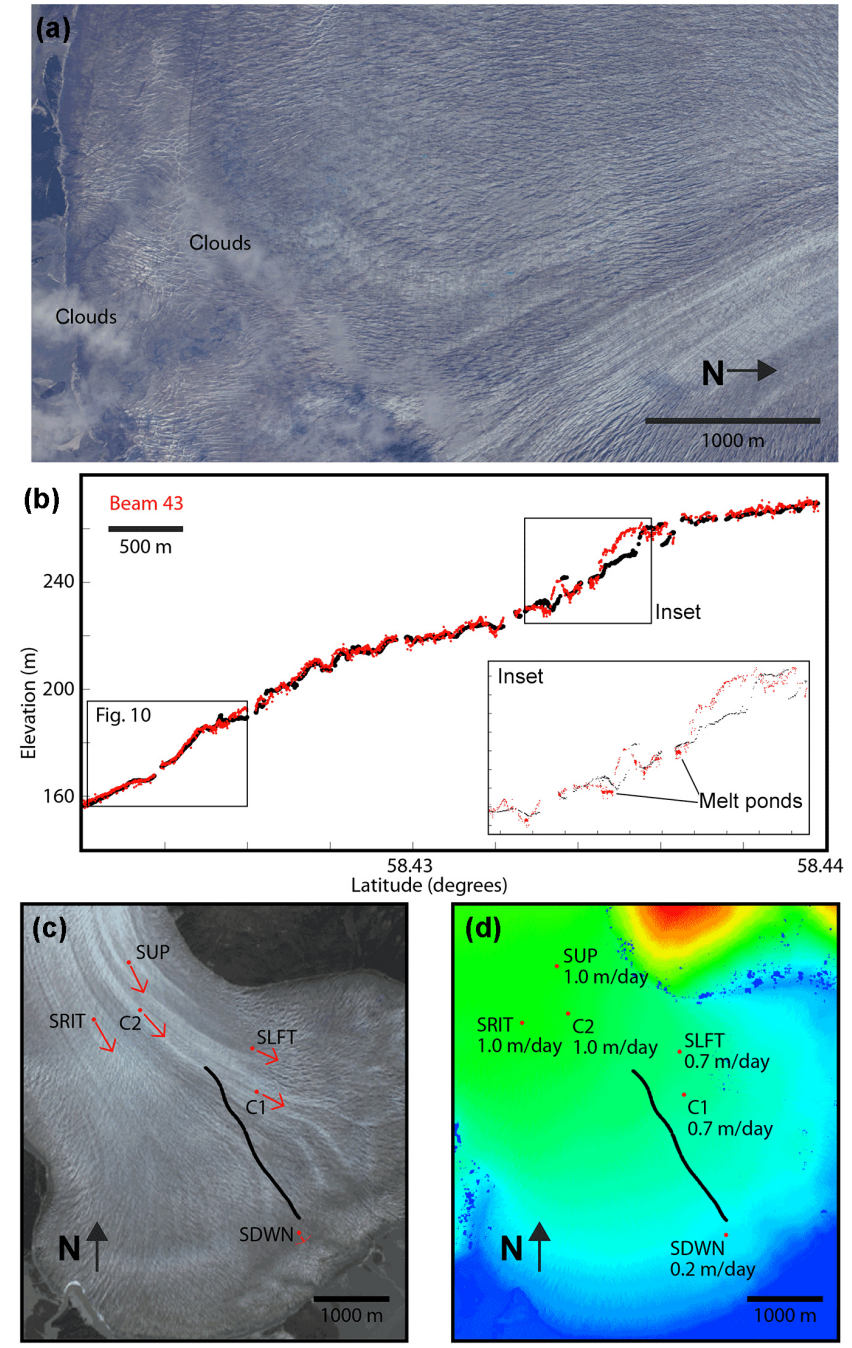

Figure 8. MABEL data over crevasse fields on the Lower Taku Glacier, from the 16 July 2014 flight. (a) Stitched MABEL camera images. (b) MABEL signal photons (red), migrated based on GPS data and corrected for an $8 \mathrm{~m}$ range bias, and elevations extracted from the WorldView-2 DEM (black). (c) WorldView-2 image (copyright DigitalGlobe, Inc.) with MABEL flight line and GPS sites (red). (d) WorldView-2 DEM (Moratto et al., 2010) with MABEL flight line and GPS sites (red).

flow along the entire MABEL data line, we chose this GPS site for data migration purposes based on proximity to the center of the data line and because the direction of flow in the northing and easting directions matched the southern end of the MABEL data line. MABEL elevations were $8 \mathrm{~m} \pm 2.5 \mathrm{~m}$ lower than the values extracted from the WorldView-2 DEM. This bias is higher than other biases assessed during this campaign, which we attribute to the following: (1) the difference between the WorldView-2 DEM elevation and true elevation, which can be on the order of meters when uncorrected (Shean et al., 2016); (2) the $3 \mathrm{~m}$ MABEL range bias, determined over the open ocean (Fig. 4); and (3) the amount of surface melt-

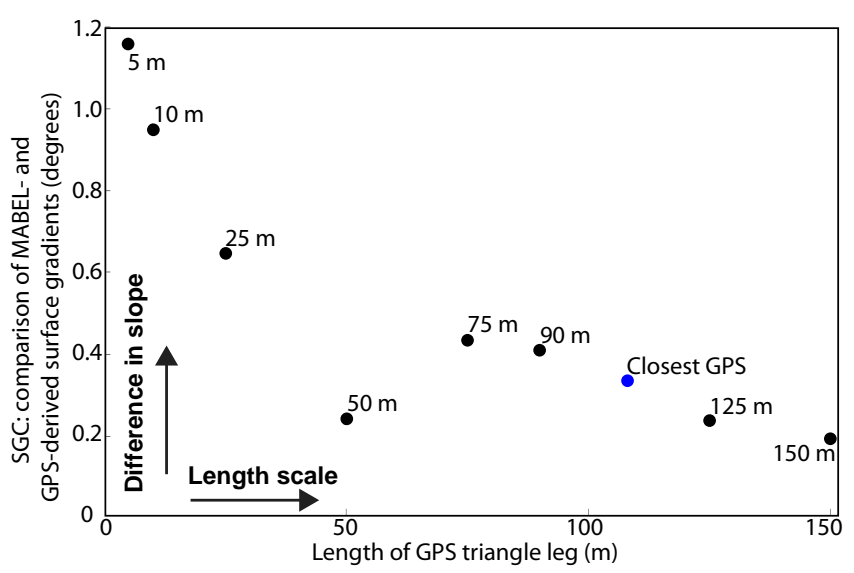

Figure 9. A surface-gradient comparison between a MABELderived surface (blue points in Fig. 3) and a series of GPS-derived surfaces, based on concentric equilateral triangles (black points here and in Fig. 3) and a surface based on the GPS survey sites that were closest to the nodes that defined the MABEL surface (blue point here and blue open circles in Fig. 3). The $x$ axis is the length of each side of the equilateral triangles (or a mean length, for the "Closest GPS" surface); the $y$ axis is the surface-gradient comparison (SGC) parameter (defined in Eq. 1), or the RSS of the difference in surface gradient $(\delta z / \delta x$ and $\delta z / \delta y)$, in degrees, between the MABELderived surface and each of the GPS-derived surfaces.

ing that occurred between June and July, which was assessed at the GPS sites to be $2.3 \mathrm{~m}$ using ablation wires. Further, we note that elevation uncertainty is a function of MABEL horizontal uncertainty $(2 \mathrm{~m})$ and surface slope; therefore, steeper terrain leads to greater overall elevation uncertainty (Brunt et al., 2014).

\subsection{Slope assessments}

Using Eq. (1), we compared the MABEL-derived surfacegradient comparison (SGC) parameters to those based on the Juneau Icefield GPS array (Fig. 9). The MABEL-derived SGC parameters were consistent with GPS-derived SGC parameters over length scales ranging from $50 \mathrm{~m}$ (just over half of the ATLAS beam spacing) to $150 \mathrm{~m}$ (just under twice the ATLAS beam spacing). The SGCs for 50 to $150 \mathrm{~m}$ spatial scales were less than $0.5^{\circ}$.

The high-resolution WorldView-2 DEM also provided a means of assessing MABEL-derived across-track slopes in steeper glacial settings. Using a method similar to that of Brunt et al. (2014), we calculated a $\sim 40 \mathrm{~m}$ across-track MABEL-derived slope and compared this with a $\sim 40 \mathrm{~m}$ across-track slope based on WorldView-2 DEM elevations. The MABEL-derived across-track slope was calculated using beams 43 and 50, migrated to match the timing of the WorldView-2 image acquisition and limited to continuous stretches of the southern part of the data line (Fig. 8b). Along-track signal-photon density for beam 48 was insufficient to allow for a $90 \mathrm{~m}$ across-track assessment. The MA- 


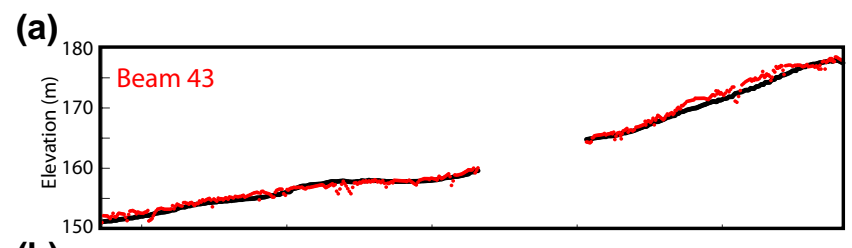

(b)

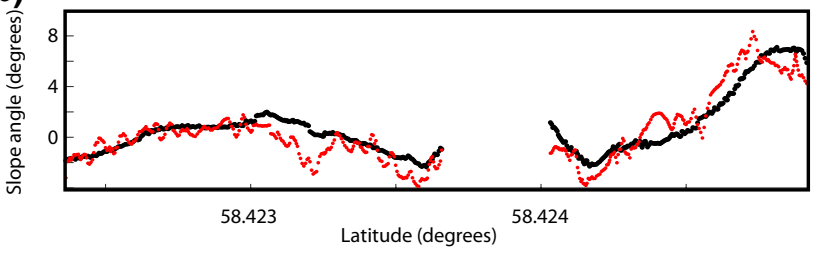

Figure 10. MABEL and DEM surfaces and slopes for a small stretch (see box in Fig. 8b) on the Lower Taku Glacier. (a) MABEL (red) and extracted DEM (black) elevations in meters, for beam 43, migrated based on GPS data and corrected for an $8 \mathrm{~m}$ range bias. (b) MABEL (red) and DEM (black) across-track slope angle in degrees, using beams 43 and 50 .

BEL data from each beam were aligned to determine alongtrack elevations and across-track slopes between beams. A DEM-derived across-track slope was calculated based on elevations that were extracted from the DEM at each interpolated MABEL data point for beams 43 and 50. Figure 10a shows a comparison between the MABEL and DEM elevations associated with beam 43, while Fig. 10b shows a comparison between MABEL-derived and DEM-derived acrosstrack slopes. The total along-track distance used in this analysis was $\sim 300 \mathrm{~m}$ (see box in Fig. $8 \mathrm{~b}$ ). The mean residual between the MABEL-derived slope and the DEM-derived slope was $0.25^{\circ}$.

\section{Discussion}

As noted above, there are some significant differences between MABEL and ATLAS depicted in Fig. 1 (e.g., number of beams, beam pattern, and altitude) and described elsewhere in this paper (e.g., footprint size, along track footprint spacing, and wavelengths). In order to relate the predicted performance of ATLAS with the measured performance of MABEL, some common metric is necessary that accounts for as many of the differences as is practicable. The signalphoton density is a metric to relate the radiometry of the two instruments. Given that the signal-photon density is generally less than that predicted for ATLAS, for a given background rate, the surface should be more easily distinguished in ATLAS data. While in theory one could use the framework developed for predicting ATLAS radiometric characteristics to make similar predictions for MABEL and therefore use MABEL data to evaluate that framework, the efficiency or radiometric throughput of MABEL has not been characterized well enough to do so. Flight data (Brunt et al., 2014) show that, for a given campaign, the measured signal-photon den- sity of MABEL changes by tens of a percent over a relatively uniform ice sheet interior. Similar changes are measured for the background rate, after consideration for sun angle is taken into account. As such, the analysis presented here cannot be used to quantitatively assess the likelihood that ATLAS will meet its measurement requirements (or the mission science objectives). What we can say is that if the ATLAS signalphoton density and signal-to-noise ratios are within $30 \%$ of its measurement requirements (and thus mimics the MABEL performance documented in this study), ATLAS can be used to measure surface slopes over both relatively flat ice-sheet interior conditions and steeper glaciers, such as the Lower Taku Glacier, and identify melt ponds. If ATLAS fully meets its measurement requirements, we expect that the definition of small-scale surface features such as crevasses and melt ponds will be correspondingly improved.

The result of this analysis indicates that the MABELderived local slope assessment, on a relatively flat glacial surface and on a $90 \mathrm{~m}$ across-track length scale, is consistent with in situ slope assessments made at spatial scales ranging from 50 to $150 \mathrm{~m}$. For a planar surface where slope is less than $1^{\circ}$, such as the interior of an ice sheet, we expect the local slope measured by a GPS survey and MABEL to be similar over a wide range of spatial scales. Any small differences observed between the two survey techniques would likely reflect (1) the non-planarity of the surface and/or (2) the sensitivity of the results to small-scale slopes or roughness captured by one measurement technique and not the other. With the good observed agreement between MABEL-derived and GPS-derived slope assessments over 50-150 m length scales (Fig. 9), we are confident that the ATLAS $90 \mathrm{~m}$ beam-spacing strategy will provide a non-aliased estimate of local slope for ice-sheet interiors $\left(<1^{\circ}\right)$ over these spatial scales. This knowledge is necessary for accurate assessments of ice-sheet surface-elevation change.

Based on our comparison with a WorldView-2-derived DEM of the Lower Taku Glacier, MABEL can also provide valid estimates of across-track slope, even in steeper terrain. Once migrated for GPS-derived ice-flow displacements, the southern part of the MABEL-derived surface elevations is in good agreement with the DEM data, and the slope comparison between MABEL-derived and DEM-derived acrosstrack slopes had a mean residual of $0.25^{\circ}$. This residual is larger than that reported over the Greenland Ice Sheet $\left(<0.05^{\circ}\right)$ by Brunt et al. (2014), a difference that we attribute to errors associated with the migration of the MABEL data (and the result of a flight line that was oblique to the local direction of ice flow). Since the GPS array on the Lower Taku Glacier was not optimized to facilitate an across-track slope comparison similar to the comparison made higher up on the Juneau Icefield (Figs. 3 and 9), we do not expect as close an agreement between the two methods of estimating acrosstrack slope.

Figures $5 \mathrm{c}$ and $6 \mathrm{~d}$ suggest that the dense along-track sampling of MABEL is sufficient to capture surface detail, in- 
cluding melt-pond information, from a single, static beam in regions of low slope, consistent with that of an ice-sheet interior. Based on the continuous nature of the surface return through the crevasse field, especially in the $1064 \mathrm{~nm}$ beam (50) in Fig. 5c, we conclude that MABEL frequently retrieves a signal from the bottom of crevasses. Further, Fig. 8b indicates that MABEL continues to provide surface detail in regions of steeper slope, including the retrieval of the steep slopes of the crevasse walls (e.g., Figs. 5c and 6d).

As previously noted, MABEL data used in this analysis had signal-photon densities that are $\sim 44 \%$ of the expected ATLAS signal-photon densities over summer ice sheets (A. Martino, personal communication, 2014). Therefore, we believe that the level of detail that will be provided by ATLAS will be sufficient to determine local surface characteristics, similar to those observed on the Lower Taku Glacier. Such knowledge is critical to determining ice-sheet surface-elevation change, as features that could compromise these calculations (such as deep crevasses) can move or advect with ice-sheet flow or be bridged seasonally and must therefore be identifiable in the ATLAS data.

The crevasse characterization we performed on the Bagley Icefield is qualitatively confirmed using the camera imagery (Fig. 5a). However, it should be noted that we have no means of quantitatively assessing the accuracy of MABEL-derived crevasse depths. Crevasses on an ice-sheet surface have an influence on albedo (Pfeffer and Bretherton, 1987). This variation in reflectance is evident in Figs. 5b, 6b, and c, where MABEL background photon counts, and the signal-to-noise ratios, change significantly. Changes in MABEL background photon densities have also been used to detect leads in sea ice (Kwok et al., 2014; Farrell et al., 2015). From Fig. 6c we note that the overall background photon counts decrease significantly over the eastern region of this plot, which is characterized by crevasses; however, this change is non-uniform. Background photon counts drop steadily to nearly zero over the two melt ponds surveyed along this transect.

Penetration of $532 \mathrm{~nm}$ wavelength light into the surface, be it a melt pond or snow, is an ongoing area of research for ICESat-2 algorithm development. MABEL geolocation uncertainty, and the fact that the 1064 and $532 \mathrm{~nm}$ beams do not have coincident footprints for more direct comparison (as the $1064 \mathrm{~nm}$ beams lead the $532 \mathrm{~nm}$ beams by $\sim 60 \mathrm{~m}$ ), compromised our ability to further interrogate this topic with this dataset, as the data could not be precisely coregistered spatially. Due to these limitations, a separate campaign with a different photon-counting laser altimeter (with both a more accurate geopositioning system and coincident 1064 and $532 \mathrm{~nm}$ footprints) was deployed to Thule, Greenland, in July and August 2015 (Brunt et al., 2015). Processing and analysis of that dataset are still ongoing.

Analysis of MABEL data over small melt ponds on the Bagley Icefield in Alaska provided a preliminary assessment of how green-wavelength photon-counting systems will interact with water on an ice surface. Based on the signal- photon elevations in Fig. 6d, and the histogram of the signal photons in Fig. 7, the total spread of the signal photons, at a wavelength of $532 \mathrm{~nm}$, is approximately 1.5 to $2 \mathrm{~m}$. Further, analysis of Landsat 8 and WorldView- 2 imagery confirm that the melt ponds in this region are approximately $2 \mathrm{~m}$ deep. These results suggest that, while there is not a distinct signal return from a melt-pond bottom, the $532 \mathrm{~nm}$ MABEL beam may be sampling the entire melt-pond water column. The $1064 \mathrm{~nm}$ MABEL beam shows evidence of a secondary return $1.5 \mathrm{~m}$ below the main signal return, due to unintended secondary pulses from the MABEL laser that occur under some operational conditions, and is likely not due to meltpond bottom returns.

Based on the surface characterization results of MABEL data from the Juneau and Bagley icefields, and the dense, six-beam sampling strategy of ATLAS, we are confident that ICESat-2 will contribute significantly to glacier studies at local and regional scales and in polar and mid-latitudes. While previous studies using satellite laser altimetry have investigated the vertical dimension of rifts in the ice sheet (e.g., Fricker et al., 2005), those studies have been limited to major ice-shelf rift systems, as opposed to smaller-scale crevasses. The $0.70 \mathrm{~m}$ along-track sampling density of each individual ATLAS beam is well suited for similar vertical dimension studies, but at finer length scales, such as those associated with alpine glacier crevasse fields.

\section{Conclusions}

Knowledge of local slope and local surface character are required to accurately determine ice-sheet surface-elevation change. The ATLAS beam geometry includes pairs of beams separated at $90 \mathrm{~m}$ across track to enable the determination of local slope in one pass, and therefore to enable the determination of ice-sheet surface-elevation change in just two passes. Based on the analysis of MABEL, ground-based GPS data, and the resultant surface gradient comparison (SGC), we conclude that the ATLAS $90 \mathrm{~m}$ beam-spacing strategy will provide a valid assessment of local slope that is consistent with the slope of an ice-sheet interior $\left(<1^{\circ}\right)$ on 50 to $150 \mathrm{~m}$ length scales. The density of along-track photon-counting lidar data is sufficient to characterize the ice-sheet surface in detail, including small-scale features such as crevasses and melt ponds. This information is required for accurate determination of ice-sheet surface-elevation change. The dense along-track sampling interval and narrow across-track beam spacing of ATLAS will provide a level of detail of mountain glaciers that has previously not been achieved from satellite laser altimetry. While studies of mountain glaciers stand to benefit greatly from ICESat-2 data, great care will need to be taken in the interpretation of elevation change of a heterogeneous surface, such as that associated with crevasses or melt ponds. 
The MABEL 2014 Alaska campaign was timed to collect data during the summer melt season to specifically investigate how $532 \mathrm{~nm}$ wavelength laser light interacts with a melting snow surface. Results from MABEL, and confirmed through analysis of Landsat 8 imagery, suggest that $532 \mathrm{~nm}$ wavelength light is likely reflecting from the surface and subsurface of the $2 \mathrm{~m}$ deep supraglacial melt ponds on the Bagley Icefield. This is an ongoing area of research for ATLAS and ICESat-2 algorithm development.

\section{Data availability}

MABEL lidar data and camera imagery are publicly available on the NASA ICESat-2 data page (http: //icesat.gsfc.nasa.gov/icesat2/data/mabel/mabel_docs.php). The NASA GSFC surface-finding algorithm is available from the authors upon request (kelly.m.brunt@nasa.gov or kaitlin.m.walsh@nasa.gov). Landsat 8 OLI imagery is available for download via the USGS EarthExplorer (http://earthexplorer.usgs.gov/). WorldView-2 imagery was acquired via the Polar Geospatial Center at the University of Minnesota; this center makes these images available to federally-funded researchers. Post-processed, ground-based GPS data from the Juneau Icefield, and ice-flow velocities from the six GPS sites on the Lower Taku Glacier, are available online, as the supplement related to this article.

\section{The Supplement related to this article is available online at doi:10.5194/tc-10-1707-2016-supplement.}

Acknowledgements. Funding for this project was through the NASA ICESat-2 Project Science Office. Funding for J. M. Amundson was provided by NSF-PLR 1303895. We acknowledge the considerable efforts of the Project, Science, and Instrument teams of NASA's ICESat-2 and MABEL missions. We thank the following people: Eugenia De Marco (ASRC Aerospace Corp., NASA/GSFC) and Dan Reed (Sigma Space Corp., NASA/GSFC) for MABEL instrument support; Scott Luthcke (NASA/GSFC), David Hancock (NASA/WFF), and Jeff Lee (NASA/WFF) for MABEL data calibration; Scott McGee and Ya' Shonti Bridgers (JIRP) for GPS field data collection and data processing support; and NASA/AFRC (specifically ER-2 pilots Tim Williams and Denis Steele) for Alaska airborne support. WorldView imagery was provided by the Polar Geospatial Center at the University of Minnesota, which is supported by NSF-PLR 1043681. GPS receivers for the survey of the terminus of the Lower Taku Glacier were provided by UNAVCO. GPS receivers for the JIRP survey were provided by Werner Stempfhuber of the Beuth University of Applied Sciences. And, finally, we thank two anonymous reviewers for their highly constructive suggestions.

Edited by: A. Kääb

Reviewed by: two anonymous referees

\section{References}

Abdalati, W., Zwally, H., Bindschadler, R., Csatho, B., Farrell, S., Fricker, H., Harding, D., Kwok, R., Lefsky, M., Markus, T., Marshak, A., Neumann, T., Palm, S., Schutz, B., Smith, B., Spinhirne, J., and Webb, C.: The ICESat-2 laser altimetry mission, Proc. IEEE, 98, 735-751, 2010.

Blair, J., Rabine, D., and Hofton, M.: The Laser Vegetation Imaging Sensor: a medium-altitude, digitisation-only, airborne laser altimeter for mapping vegetation and topography, ISPRS J. Photogramm., 54, 115-122, 1999.

Brunt, K., Neumann, T., Markus, T., and Walsh, K.: MABEL photon-counting laser altimetry data for ICESat-2 simulations and development, AGU Fall Meeting, San Francisco, CA, 2013.

Brunt, K., Neumann, T., Walsh, K., and Markus, T.: Determination of local slope on the Greenland Ice Sheet using a multibeam photon-counting lidar in preparation for the ICESat-2 mission, IEEE Geosci. Remote S., 11, 935-939, 2014.

Brunt, K., Neumann, T., and Markus, T.: SIMPL/AVIRIS-NG Greenland 2015; Flight Report, NASA Technical Memorandum, 17977, 23 pp., 2015.

Deems, J., Painter, T., and Finnegan, D.: Lidar measurement of snow depth: a review, J. Glaciol., 59, 467-479, 2013.

Farrell, S., Brunt, K., Ruth, J., Kuhn, J., Connor, L., and Walsh, K.: Sea ice freeboard retrieval using digital photon-counting laser altimetry, Ann. Glaciol., 56, 167-174, 2014.

Fricker, H., Bassis, J., Minster, B., and MacAyeal, D.: ICESat's new perspective on ice shelf rifts: The vertical dimension, Geophys. Res. Lett., 32, L23S08, doi:10.1029/2005GL025070, 2005.

Hodgson, M. and Bresnahan, P.: Accuracy of airborne lidar-derived elevation: empirical assessment and error budget, Photogramm. Eng. Remote. Sens., 70, 331-340, 2004.

Krabill, W., Abdalati, W., Frederick, E., Manizade, S., Martin, C., Sonntag, J., Swift, R., Thomas, R., and Yungel, J.: Aircraft laser altimetry measurement of elevation changes of the Greenland ice sheet: Technique and accuracy assessment, J. Geodyn., 34, 357376, 2002.

Kwok, R., Cunningham, G., Manizade, S., and Krabill, W.: Arctic sea ice freeboard from IceBridge acquisitions in 2009: Estimates and comparisons with ICESat, J. Geophys. Res., 117, C02018, doi:10.1029/2011JC007654, 2012.

Markus, T., Neumann, T., Martino, A., Abdalati, W., Brunt, K., Csatho, B., Farrell, S., Fricker, H., Gardner, A., Harding, D., Jasinski, M., Kwok, R., Magruder, L., Lubin, D., Luthcke, S., Morison, J., Nelson, R., Neuenschwander, A., Palm, S., Popescu, S., Shum, C., Schutz, B., Smith, B., Yang, Y., and Zwally, J.: The Ice, Cloud, and land Elevation Satellite-2 (ICESat-2): Science requirements, concept, and implementation, Remote Sens. Environ., in review, 2016.

McGill, M., Markus, T., Scott, V., and Neumann, T.: The Multiple Altimeter Beam Experimental Lidar (MABEL), an airborne simulator for the ICESat-2 mission, J. Atmos. Oceanic Technol., 30, 345-352, 2013.

Moratto, Z, Broxton, M., Beyer, R., Lundy, M., and Husmann, K.: Ames Stereo Pipeline, NASA's Open Source Automated Stereogrammetry Software, presented at the Lunar and Planetary Science Conference, Houston, Texas, 2010.

Moussavi, M.: Quantifying supraglacial lake volumes on the Greenland ice sheet from spaceborne optical sensors, Ph.D. Thesis, University of Colorado at Boulder, AAT 3704777, ISBN: 
9781321773804, Dissertation Abstracts International, Vol. 7610, 128 pp., 2015.

Moussavi, M., Abdalati, W., Pope, A., Scambos, T., Tedesco, M., MacFerrin, M., and Grigsby, S.: Derivation and validation of supraglacial lake volumes on the Greenland Ice Sheet from highresolution satellite imagery, Remote Sens. Environ., 183, 294303, 2016.

NASA Goddard Space Flight Center: MABEL lidar data, MABEL ICESat-2 simulation data, Version 9, Greenbelt, Maryland USA, http://icesat.gsfc.nasa.gov/icesat $/$ data/mabel/mabel_ docs.php.11/1/2014, 2014.

NASA Landsat 8 Program: Landsat 8 OLI, Landsat OLI scene LC80640182014185LGN00, L1T, USGS, Sioux Falls, 07/05/2014, 2014.

Pfeffer, W. and Bretherton, C.: The effect of crevasses on the solar heating of a glacier surface, The Physical Basis of Ice Sheet Modelling, IAHS Publication, 170, 191-205, 1987.

Pope, A., Scambos, T. A., Moussavi, M., Tedesco, M., Willis, M., Shean, D., and Grigsby, S.: Estimating supraglacial lake depth in West Greenland using Landsat 8 and comparison with other multispectral methods, The Cryosphere, 10, 15-27, doi:10.5194/tc10-15-2016, 2016.
Shean, D., Alexandrov, O., Moratto, Z., Smith, B., Joughin, I., Porter, C., and Morin, P.: An automated, open-source pipeline for mass production of digital elevation models (DEMs) from very-high-resolution commercial stereo satellite imagery, ISPRS J. Photogramm., 116, 101-117, 2016.

Young, D., Lindzey, L., Blankenship, D., Greenbaum, J., De Gorordo, A., Kempf, S., Roberts, J., Warner, R., Van Ommen, T., Siegert, M., and Le Meur, E.: Land-ice elevation changes from photon-counting swath altimetry: first applications over the Antarctic ice sheet, J. Glaciol., 61, 17-28, 2015.

Zwally, H., Li, J., Brenner, A., Beckley, M., Cornejo, H., DiMarzio, J., Giovinetto, M., Neumann, T., Robbins, J., Saba, J., Yi, D., and Wang, W.: Greenland ice sheet mass balance: distribution of increased mass loss with climate warming; 2003-2007 versus 1992-2002, J. Glaciol., 57, 88-102, 2011. 